\title{
Psychological and Physiological Adaptations to Sperm Competition in Humans
}

\author{
Todd K. Shackelford \\ Florida Atlantic University
}

\author{
Nicholas Pound \\ Brunel University
}

\author{
Aaron T. Goetz \\ Florida Atlantic University
}

\begin{abstract}
Postcopulatory competition between males, in the form of sperm competition, is a widespread phenomenon in many animal species. The extent to which sperm competition has been an important selective pressure during human evolution remains controversial, however. The authors review critically the evidence that human males and females have psychological, behavioral, and physiological adaptations that evolved in response to selection pressures associated with sperm competition. The authors consider, using evidence from contemporary societies, whether sperm competition is likely to have been a significant adaptive problem for ancestral humans and examine the evidence suggesting that human males have physiological and psychological mechanisms that allow for "prudent" sperm allocation in response to variations in the risk of sperm competition.
\end{abstract}

Keywords: sperm competition, postcopulatory competition, evolutionary psychology

Darwin (1871) described two mechanisms of sexual selection: intrasexual competition among males or females for sexual access to members of the opposite sex and intersexual selection involving differential mate choice of members of the opposite sex. Because members of the sex that invests more in offspring are more selective with respect to with whom they mate (Trivers, 1972), sexual selection, as Darwin noted, usually involves males competing for mating opportunities with females and females choosing among them. Studies of sexual selection have generally focused on these processes (for an overview, see Andersson, 1994); however, for some time now it has been recognized that sexual selection also may involve processes that occur after the initiation of

Todd K. Shackelford and Aaron T. Goetz, Department of Psychology, Florida Atlantic University; Nicholas Pound, Centre for Cognition and Neuroimaging, Brunel University, Uxbridge, England.

Todd K. Shackelford and Nicholas Pound contributed equally to this article.

Correspondence concerning this article should be addressed to Todd K. Shackelford, Department of Psychology, Florida Atlantic University, 2912 College Avenue, Davie, FL 33314. E-mail: tshackel@fau.edu copulation. Parker (1970) first noted that when a female mates with multiple males there can be competition between sperm from different males to fertilize her gamete(s), that is, sperm competition. More recently, it has been recognized that females may influence the outcome of sperm competition and continue to select among males after the initiation of copulation through mechanisms of cryptic female choice (Eberhard, 1996; Thornhill, 1983).

In this article, we examine critically the evidence that human males and females have adaptations to sperm competition and consider whether human females have mechanisms for postcopulatory sperm choice. When sperm competition occurs, fertilization success may be determined, in part, by the outcome of direct interactions between sperm from rival males. Consequently, if sperm competition has been an important selective pressure during human evolution, then adaptations to sperm competition might be found at the cellular level in aspects of spermatozoal morphology and physiology. The selective pressures associated with sperm competition also may have generated adaptations in many aspects of male and female anatomy, physiology, psychology, and behavior. 


\section{Sperm Competition in Nonhuman Species}

Sperm competition has been documented or inferred to exist in many species, ranging from molluscs (Baur, 1998) and insects (Simmons, 2001) to birds (Birkhead \& Møller, 1992) and mammals (Gomendio, Harcourt, \& Roldán, 1998). In species with internal fertilization, there is the potential for sperm competition whenever a female mates with multiple males in a sufficiently short period of time that live sperm from two or more males are present in her reproductive tract when she is fertile. The outcome of such competition, notwithstanding mating order effects, depends on a "raffle" or "lottery" principle; that is, a particular male can increase the probability of siring a female's offspring by inseminating more sperm (Parker, 1970, 1990). The costs of ejaculate production are nontrivial, however (Dewsbury, 1982; Nakatsuru \& Kramer, 1982; Olsson, Madsen, \& Shine, 1997), and repeated ejaculation can lead to sperm depletion (Ambriz et al., 2002; Preston, Stevenson, Pemberton, \& Wilson, 2001). Therefore, males must trade off ejaculate production costs against the potential benefits of delivering large numbers of sperm.

The potential benefits of delivering an ejaculate with greater sperm numbers depend on the probability that a female's reproductive tract (in the case of internal fertilizers) or the spawning area (in the case of external fertilizers) contains or will soon contain sperm from a rival male, that is, the risk of sperm competition. Consequently, one of the first hypotheses generated by sperm competition theory was that males will deliver more sperm when the risk of sperm competition is high (Parker, 1982, 1990). Across species, therefore, investment in sperm production is predicted to depend on the risk of sperm competition (Parker, 1998). Within species, males are predicted to allocate their sperm "prudently" and to inseminate more sperm when the risk of sperm competition is high (Wedell, Gage, \& Parker, 2002).

In accordance with the first prediction, investment in sperm production has been shown to be greater in species with high levels of sperm competition. For example, in primates (Harcourt, Harvey, Larson, \& Short, 1981), birds (Møller, 1988b), ungulates (Ginsberg \& Rubenstein, 1990), frogs (Jennions \& Passmore, 1993), and butterflies (M. J. G. Gage, 1994), testis size relative to body size (an index of investment in sperm production) is correlated positively with the frequency with which females engage in polyandrous matings. Moreover, recent work has demonstrated experimentally that, in yellow dung flies (Scathophaga stercoraria), exposure to mating environments with high levels of sperm competition can produce significant increases in testis size after only 10 generations (Hosken \& Ward, 2001).

In addition to the evidence that, across species, investment in sperm production depends on the risk of sperm competition, evidence is accumulating that individual males are capable of prudent sperm allocation (for reviews, see Parker, Ball, Stockley, \& Gage, 1997; Wedell et al., 2002). Experiments have demonstrated that males in many species are capable of adjusting the number of sperm they deliver from one insemination to the next in response to cues of sperm competition risk (e.g., Cook \& Wedell, 1996; M. J. G. Gage, 1991; M. J. G. Gage \& Baker, 1991). Males must rely on cues predictive of sperm competition risk because this risk often cannot be assessed directly. These cues could be any auditory, olfactory, tactile, or visual stimuli that reliably predict whether a female's reproductive tract (or spawning area) contains or will soon contain sperm from rival males.

There is experimental evidence that males of various species respond adaptively to cues of elevated sperm competition risk, including male mating status in species in which it predicts the likelihood of mating with an already-mated female (Cook \& Wedell, 1996) and female mating status when it is detectable (A. R. Gage \& Barnard, 1996). In addition, males of various species appear to be sensitive to the operational sex ratio, or the mere presence of one or more rival males, during a particular mating event. Mealworm beetles (Tenebrio molitor; M. J. G. Gage \& Baker, 1991) and mediterranean fruitflies (Ceratitis capitata; M. J. G. Gage, 1991), for example, inseminate more sperm when mating in the presence of rival males. And field crickets (Gryllodes supplicans) and house crickets (Acheta domesticus) increase the number of sperm they inseminate in proportion to the number of rivals present (A. R. Gage \& Barnard, 1996).

Other species known to adjust the number of sperm they deliver in response to the presence of rival males (or during group spawning) include bucktooth parrotfish (Sparisoma radians; 
Marconato \& Shapiro, 1996) and bluehead wrasse (Thalassoma bifasciatum; Shapiro, Marconato, \& Yoshikawa, 1994). In mammals, male rats (Rattus norvegicus) adjust the number of sperm they inseminate according to the amount of time they have spent "guarding" a particular female before copulation (Bellis, Baker, \& Gage, 1990). In addition, male rats inseminate more sperm when mating in the presence of a rival male (Pound \& Gage, 2004). Similarly, male meadow voles (Microtus pennsylvanicus) inseminate more sperm when they mate in the presence of another male's odors (DelBarco-Trillo \& Ferkin, 2004).

Among species that practice social monogamy, the mating system in which males and females form long-term pair bonds but also pursue extrapair copulations, extrapair copulations by females create the primary context for sperm competition (Birkhead \& Møller, 1992; Smith, 1984). A male whose female partner engages in extrapair copulation is at risk of cuckoldry and its associated costs, which include loss of the time, effort, and resources the male spent attracting his partner; potential misdirection of his current and future resources to a rival's offspring; and loss of his mate's investment in any offspring he may have sired with her in the future (Trivers, 1972). Consequently, in species with paternal investment in offspring, selection will have favored the evolution of adaptations that decrease the likelihood of being cuckolded (Daly, Wilson, \& Weghorst, 1982; Trivers, 1972; M. Wilson \& Daly, 1992).

Anticuckoldry tactics fall into three categories: preventative tactics, designed to minimize female infidelity; sperm competition tactics, designed to minimize conception risk in the event of female infidelity; and differential paternal investment, designed to allocate paternal investment prudently in the event that female infidelity may have resulted in conception (Daly \& Wilson, 1980, 1995; Platek, 2003; Shackelford, 2003; M. Wilson \& Daly, 1992). It is expected that, for a given mating interaction, performance of these tactics will tend to proceed in the sequence just outlined. Although a male's best strategy may be to prevent female infidelity, if he is unsuccessful in this effort he could benefit by attempting to prevent conception by a rival male. If he is unsuccessful in preventing conception by a rival male, he could benefit by adjusting paternal effort according to available paternity cues (Daly \& Wilson, 1982). Perfor- mance of one tactic therefore does not necessitate neglect of another; indeed, a reproductively wise strategy would be to engage in all three categories of anticuckoldry tactics.

Male swallows (Hirundo rustica), a socially monogamous bird species, have been observed performing preventative tactics, sperm competition tactics, and differential paternal investment (Møller, 1985, 1987, 1988a, as cited in M. Wilson \& Daly, 1992). Male swallows guard their mates while their mates are fertile (Møller, 1987); they adjust their rate of in-pair copulation relative to the proximity of rival males (Møller, 1985); and they adjust paternal effort according to the frequency of their mate's extrapair copulations (Møller, 1988a). With these three categories of anticuckoldry tactics at their disposal, male swallows appear well equipped to minimize the fitness costs associated with female extrapair copulations. Similarly effective suites of anticuckoldry tactics are expected in other socially monogamous species, and examining the adaptive problems and resultant evolved solutions to these problems in nonhumans may provide insight into the adaptive problems and evolved solutions in humans (and vice versa). Shackelford and LeBlanc (2001) argued that because humans share similar adaptive problems with insects (e.g., mate retention) and birds (e.g., extrapair copulations), humans, insects, and birds may share similar solutions to these adaptive problems. Shackelford and LeBlanc argued that applying a comparative evolutionary psychological approach to the study of evolved solutions to problems of sperm competition may lead to the discovery of an arsenal of anticuckoldry tactics in men.

\section{Has Sperm Competition Been an Adaptive Problem for Humans?}

The issue of whether sperm competition has been an important selective force during human evolution is controversial. Smith (1984) argued that the comparatively large size of the human penis, and the fact that human testes are somewhat larger in relation to body size than are those of monogamous primates (Short, 1981), suggests that sperm competition has been a recurrent feature of human evolutionary history. Smith suggested that facultative polyandry (i.e., female sexual infidelity) would have been the most common reason for the simultaneous presence of live 
sperm from two or more men in the reproductive tract of an ancestral woman. Smith noted that other contexts in which sperm competition might have occurred include consensual communal sex, courtship, rape, and prostitution but argued that these contexts may not have occurred with sufficient frequency over human evolutionary history to provide selection pressures for adaptations to sperm competition equivalent to female infidelity.

In socially monogamous species, extrapair copulations by females create the primary context for sperm competition (Birkhead \& Møller, 1992; Smith, 1984). Consequently, the extent to which sperm competition occurred in ancestral human populations would have depended on rates of female sexual infidelity. The ubiquity and power of male sexual jealousy provides evidence of an evolutionary history of female infidelity and thus perhaps also of sperm competition. Male sexual jealousy could evolve only if female sexual infidelity was a recurrent feature of human evolutionary history (see, e.g., Buss, 2000; Buss, Larsen, Westen, \& Semmelroth, 1992; Daly et al., 1982; Symons, 1979), and female infidelity increases the likelihood that sperm from two or more men occupied simultaneously the reproductive tract of a particular woman.

Moreover, a recent genetic study provides additional evidence consistent with the view that sperm competition has been a recurrent feature of human evolutionary history. Investigating primate genes that code for proteins involved in the production and function of sperm, Wyckoff, Wang, and Wu (2000) found that these genes have been evolving at a much faster rate than most other human genes. Furthermore, such genes have been evolving at a rate comparable to parallel genes in the highly promiscuous chimpanzee and much faster than in the monandrous gorilla. This indicates that sexual selection, perhaps in the form of sperm competition, has been an important selection pressure during recent human evolution. If this is the case, however, then evidence of specific adaptations to sperm competition in men and women should be expected. Moreover, there should be evidence that ancestral human females would have behaved in such a way as to generate sperm competition.

\section{Do Women Generate Sperm Competition?}

Evolutionary accounts of human sexual psychology have emphasized the benefits to men of short-term mating and sexual promiscuity (e.g., Buss \& Schmitt, 1993; Symons, 1979). If men are to pursue short-term sexual strategies, however, there must be women who mate nonmonogamously. Moreover, if ancestral women never engaged in short-term mating, men could not have evolved a strong desire for sexual variety (Schmitt et al., 2003; Schmitt, Shackelford, \& Buss, 2001; Schmitt, Shackelford, Duntley, Tooke, \& Buss, 2001; Smith, 1984).

Ancestral women may have benefited from facultative polyandry in several ways (Smith, 1984; for a review, see Greiling \& Buss, 2000). One of the most important potential benefits was acquisition of resources, either in direct exchange for sex with multiple men (Symons, 1979) or by creating paternity confusion as a means to elicit paternal investment (Hrdy, 1981). Alternatively, ancestral women may have benefited indirectly by accepting resources and parental effort from a primary mate while copulating opportunistically with men of superior genetic quality (Smith, 1984; Symons, 1979). Extrapair sex also might have been useful as insurance against the possibility that a primary mate was infertile, and in unpredictable environments it may be advantageous for women to ensure that offspring are sired by different men and are thus genetically diverse (Smith, 1984). Jennions and Petrie (2000) provided a comprehensive review of the genetic benefits to females of multiple mating.

Multiple mating by women is a prerequisite for sperm competition to occur, but not all patterns of polyandry will generate postcopulatory competition between men. For sperm competition to occur, women must copulate with two or more men in a sufficiently short period of time such that there is overlap in the competitive life spans of the rival ejaculates. The length of this competitive "window" might be as short as 2 or 3 days (Gomendio \& Roldán, 1993) or as long as 7 to 9 days (Smith, 1984). Using an intermediate estimate of 5 days, Baker and Bellis (1995) argued that the questionnaire data they collected on female sexual behavior indicated that $17.5 \%$ of British women "double mated" at some point during the first 50 copulations in their lifetimes. Such double matings do not always lead to sperm competition in 
contemporary environments (because barrier contraceptives may be used), but they represent a pattern of behavior that would have led to sperm competition in ancestral environments.

Gomendio et al. (1998), however, questioned Baker and Bellis's (1995) estimate of the frequency with which women double mate, because the data were derived from a self-selected sample of women from the readership of a popular magazine who may have been more sexually active than the female population at large. Moreover, Gomendio et al. argued that the competitive life span of an ejaculate within the female reproductive tract is probably around 3 days rather than 5 days. Whichever estimate is accepted, there are only limited data available on the frequency with which women in contemporary populations might behave in ways that could potentially generate sperm competition, because large-scale studies of sexual behavior have not collected data on the frequency with which women double mate specifically. Many studies, however, have recorded how often women engage in concurrent sexual relationships more generally.

Not all concurrent sexual relationships involve copulations with different men within a sufficiently short space of time to be considered double matings, but it is likely that many do. Even using Gomendio et al.'s (1998) conservative estimate of the competitive life span of an ejaculate (3 days), sperm competition would be very likely to occur if a woman engages in concurrent sexual relationships with two men that involve weekly copulation with each partner. Consequently, the rate at which women participate in concurrent sexual relationships provides an index of the likelihood of sperm competition in a population. Gomendio et al. argued that survey data indicate that only $2 \%$ of women in Britain have engaged in concurrent sexual relationships in the past year and, consequently, that sperm competition is likely to be a relatively infrequent occurrence. However, a major study of sexual behavior in Britain-the National Survey of Sexual Attitudes and Lifestyles, conducted between 1999 and 2001 (Johnson et al., 2001)—revealed that 9\% of women overall, and 15\% of those 16-24 years of age, reported having had concurrent sexual relationships with men during the preceding year. In a large study of sexual behavior conducted in the United States, Laumann, Gagnon, Michael, and Michaels (1994) found that, al- though only about $20 \%$ of young women reported having multiple partners during the previous year, of those who reported having many (five or more), $83 \%$ also reported that at least two of these relationships were concurrent.

Sperm competition may arise as a by-product of female behaviors that function to increase the probability that a female will conceive offspring sired by a male other than her primary mate. However, Bellis and Baker (1990) argued that women "schedule" their copulations in a way that actively promotes sperm competition, thus allowing their $\operatorname{egg}(\mathrm{s})$ to be fertilized by the most competitive sperm. They reported questionnaire data indicating that women are more likely to double mate when the probability of conception is highest, suggesting that women may promote sperm competition. Bellis and Baker argued that the results cannot be attributed to a male preference for copulation with women at peak fertility, because this would also lead to an increase in the frequency of in-pair copulation during fertile phases of the menstrual cycle, rather than just an increase in the frequency of extrapair copulations. They may, however, have been too quick to dismiss the possibility that men prefer to copulate with women during peak fertility. Because women may be attempting to secure genetic benefits from their extrapair partners (see Gangestad \& Simpson, 2000; Greiling $\&$ Buss, 2000), they are predicted to prefer to copulate with extrapair partners when conception is highest and might simultaneously avoid copulation with an in-pair partner while seeking extrapair sex. Thus, although her in-pair partner might prefer to copulate with her precisely during the peak fertility phase of her cycle, this may not be reflected in her actual pattern of copulations.

\section{Polyandrous Sex in Women's Fantasies}

Sexual fantasy may provide a "window" through which to view the evolved psychological mechanisms that motivate sexual behavior (Ellis \& Symons, 1990; Symons, 1979). A large empirical literature has addressed sex differences in sexual fantasy, and much of this work has been conducted from an evolutionary perspective (see, e.g., Ellis \& Symons, 1990; G. D. Wilson, 1987, 1997; G. D. Wilson \& Lang, 1981; see Leitenberg \& Henning, 1995, for a review of empirical work on sexual fantasy). This work documents several marked sex dif- 
ferences in the content of sexual fantasies, consistent with hypotheses generated from Trivers's (1972) theory of parental investment and sexual selection. For example, given the asymmetric costs associated with sexual reproduction, sexual access to mates limits reproductive success for males more than for females. Consequently, it has been hypothesized that men more than women will have sexual fantasies that involve multiple, anonymous sexual partners who do not require an investment of time, energy, or resources before granting sexual access (e.g., Ellis \& Symons, 1990), and empirical investigations have confirmed this hypothesis. Indeed, one of the largest sex differences occurs for fantasies about having sex with two or more members of the opposite sex concurrently, with men more than women reporting this fantasy (see review by Leitenberg \& Henning, 1995).

Tests of the hypothesis that men more than women fantasize about concurrent sex with two or more partners have, however, inadvertently provided data on women's polyandrous sexual fantasies. Although this work clearly indicates that men are more likely than women to report fantasies of concurrent sex with multiple partners, polyandrous sex is certainly something about which women fantasize. In a large survey study, for example, Hunt (1974) found that 18\% of women report fantasies of polyandrous sex, imagining themselves as a woman having sex with two or more men concurrently. G. D. Wilson (1987) surveyed nearly 5,000 readers of Britain's top-selling daily newspaper about their favorite sexual fantasy and performed content analyses on the responses of a random subsample of 600 participants. Polyandrous sex was the key element of the favorite sexual fantasy reported by $15 \%$ of female participants.

Studies involving smaller samples of participants also provide evidence that polyandry is a common theme of women's sexual fantasies, albeit less common than for men. For example, Rokach (1990) reported that, although sex with more than one partner accounted for $14 \%$ of the sexual fantasies reported by a sample of 44 men, it accounted for $10 \%$ of the fantasies reported by a sample of 54 women. Person, Terestman, Myers, Goldberg, and Salvadori (1989) and Pelletier and Herold (1988) documented that $27 \%$ and $29 \%$, respectively, of the women sampled in their studies reported fantasies of polyandrous sex. Fully $41 \%$ of women sampled by Arndt, Foehl, and Good (1985) reported fan- tasies involving sex with two men at the same time, and Price and Miller (1984) reported that polyandrous sex was among the 10 most frequently reported fantasies in a small sample of college women.

If sexual fantasy reflects sexual desires and preferences that might sometimes be acted on, then previous research indicates that polyandrous sex is not an unlikely occurrence, particularly given the well-established finding that women more than men are the "gatekeepers" of sexual access, including when, where, and the conditions under which copulation occurs (see, e.g., Buss, 2004; Symons, 1979). If, as Symons (1979) has argued (see also Buss, 2004; Ellis \& Symons, 1990), sexual fantasy provides a window through which to view evolved human psychology, then human female sexual psychology may include design features dedicated to the pursuit of polyandrous sex, with the consequence of promoting sperm competition.

\section{Men's Adaptations to Sperm Competition}

Sperm competition can take one of two forms: contest competition, in which rival ejaculates actively interfere with each other's ability to fertilize an ovum or ova, and scramble competition, which is more akin to a simple race or lottery. In mammals, there are theoretical reasons to believe that most sperm competition takes the form of a scramble, and modeling studies and experimental findings support this view (Gomendio et al., 1998). Male adaptations to scramble competition are likely to take the form of physiological, anatomical, and behavioral features that increase the male's chances of fertilizing an ovum or ova in a competitive environment in which the ability to deliver large numbers of sperm is a crucial determinant of fertilization success.

\section{Is There Evidence of Prudent Sperm Allocation by Men?}

When investigating adaptations to sperm competition in men, there are two closely related but distinct questions that can be asked. First, do men have adaptations that evolved to deal with high levels of sperm competition? Second, do they have adaptations that evolved to deal with variable levels of sperm competition? Across species, investment in sperm pro- 
duction is predicted to depend on the risk of sperm competition. Accordingly, adaptations to high levels of sperm competition will include anatomical, physiological, and behavioral traits that facilitate the delivery of large numbers of sperm during copulation. However, when the risk of sperm competition is variable, individual males should allocate their sperm in a prudent fashion and inseminate more sperm when the risk is higher. Consequently, adaptations to variable levels of sperm competition are likely to take the form of traits that enable males to adjust the number of sperm they inseminate according to variations in sperm competition risk.

It is possible that adaptations to variable levels of sperm competition are present in species for which overall levels are not especially high but sperm competition is a sufficiently frequent occurrence to select for mechanisms that allow prudent sperm allocation. In fact, it could be argued that prudent sperm allocation is likely to be particularly important in species in which investment in sperm production is not great, because sperm depletion is more likely to occur. Relative to other primates, human ejaculates do not contain especially large numbers of sperm (Baker \& Bellis, 1995; Dixson, 1998). Men, therefore, do not appear to be adapted to particularly high levels of sperm competition. Nevertheless, it may be the case that men have adaptations that allow them to allocate sperm prudently as sperm competition risk varies.

The number of sperm contained in a man's ejaculate varies considerably from one ejaculate to the next (e.g., Mallidis, Howard, \& Baker, 1991; Read \& Schnieden, 1978; Schwartz, Laplanche, Jouannet, \& David, 1979). Although clinicians have tended to treat this intraindividual variability as "noise" or as a barrier to determining the "true" values of a man's semen parameters, predictions generated by sperm competition theory have led researchers to examine the possibility that some of this variability might reflect prudent sperm allocation in the face of temporal variations in the risk of sperm competition. Whether or not such variation is patterned adaptively in contemporary environments, it is possible that it may reflect the functioning of mechanisms that evolved to deal with variations in the risk of sperm competition in ancestral environments.

Men display prudent sperm allocation in at least one fundamental sense: Sperm are not emitted continuously but instead are ejected during discrete ejaculatory events that occur in response to sexual stimulation of sufficient intensity and duration. Sperm are emitted during spontaneous nocturnal events and via masturbation, both of which seem wasteful. There is evidence of prudent sperm allocation, however, in that masturbatory ejaculates typically contain fewer sperm than do copulatory ejaculates (Zavos, 1985; Zavos \& Goodpasture, 1989). The only published evidence, however, indicating that men can adjust ejaculate composition in response to adaptively relevant aspects of their sociosexual environment was reported in a series of articles by Baker and Bellis.

In 1989, Baker and Bellis first reported that the number of sperm inseminated by men during copulation varied according to hypotheses generated by sperm competition theory (Baker \& Bellis, 1989b). In their study, 10 heterosexual couples provided semen specimens collected via masturbation and others collected during copulation using nonspermicidal condoms. Participants also provided information about the time since their most recent ejaculation, the time since their most recent copulation, and the percentage of time the couple had spent together since the most recent copulation. Although participants provided multiple specimens, the analysis was restricted to the first specimen provided in each of the two experimental contexts (masturbatory and copulatory). For the 10 copulatory specimens, there was a significant negative rank-order correlation between the percentage of time the couple had spent together since their most recent copulation and the number of sperm in the ejaculate. No such relationship was identified for masturbatory ejaculates. If the percentage of time spent apart from a partner is a reliable cue of the risk of female double mating, then these findings are consistent with the hypothesis that there is a positive association between number of sperm inseminated and risk of sperm competition (Parker, 1970, 1982).

What Baker and Bellis (1989b) reported, however, was a between-subjects relationship between sperm competition risk and ejaculate composition, that is, an observation that, for a sample of 10 couples, men who had spent the most time apart from their partners since their most recent copulation produced ejaculates containing the most sperm. This is not necessarily evidence of prudent sperm allocation, however, because it could be the 
case that men who tend to produce larger ejaculates also tend to spend a greater proportion of their time between copulations apart from their partners. Moreover, this relationship could be mediated by between-male differences in testicular size and associated levels of testosterone production if variability in these characteristics predicts semen parameters and certain aspects of sexual behavior.

In a follow-up to this initial report, Baker and Bellis (1993a) attempted to address the aforementioned problems by including in their analyses more than one ejaculate from each couple that participated in this second study. Twentyfour couples provided a total of 84 copulatory ejaculates. As a means of assessing whether the number of sperm inseminated by a man depended on the percentage of time spent together since the couple's most recent copulation, only those copulatory specimens that were preceded by an ejaculation also produced during an inpair copulation (IPC) were included in the analyses (IPC-IPC ejaculates). Forty specimens produced by 5 men were included in the final analysis, and for these specimens a nonparametric test based on ranks indicated a negative association between the number of sperm inseminated and the proportion of time the couple had spent together since their most recent copulation.

This was the first evidence of ejaculate adjustment by men from one copulation to the next in response to a cue indicating temporal variation in the risk of sperm competition. It should be noted, however, that 33 of the 40 specimens included in the ranking test were produced by just 2 men. Moreover, although data were presented for the first IPC-IPC ejaculates produced by all 15 couples who provided copulatory specimens, an analysis similar to that presented in the 1989 article was not reported. We conducted this analysis using the 1993 data, and results revealed that, for the first IPC-IPC ejaculate produced by each couple, the negative rank-order correlation between the number of sperm inseminated by a man and the percentage of time spent together with his partner since their most recent copulation was marginally statistically significant $(r=-.50, p=$ .058).

Aside from the small sample size in Baker and Bellis's (1993a) demonstration of prudent sperm allocation by individual men, a number of additional methodological concerns have led some researchers to be skeptical of the findings. The reasons for doubting the reliability, validity, and generalizability of Baker and Bellis's findings, however, have rarely been articulated in articles published in peer-reviewed journals. One concern is the possibility that the people who participated in this intrusive research may not have been representative of the population at large. Recruited from the staff of and postgraduate students in a biology department, the participants might have had some knowledge of the experimental hypothesis. It is not clear, however, how such knowledge could affect semen parameters. Knowledge about the experimental hypothesis could have affected the sexual behavior of the participants, and there is evidence that semen parameters are subject to behavioral influences (Pound, Javed, Ruberto, Shaikh, \& Del Valle, 2002; Zavos, 1988; Zavos, Kofinas, Sofikitis, Zarmakoupis, \& Miyagawa, 1994). However, evidence that men are able to adjust their semen parameters in response to the demand characteristics of an experiment would perhaps be more remarkable than evidence of prudent sperm allocation in the face of cues of sperm competition risk.

Baker and Bellis (1993a) argued that an increase in the number of sperm inseminated by a man in response to a decrease in the proportion of time spent with his partner since the couple's most recent copulation is an adaptive response to a cue of increased sperm competition risk. Several alternative interpretations are possible, however. For example, changes in ejaculate composition may be secondary to changes in female sexual behavior induced by partner absence. Women who have spent a smaller proportion of time together with their partner since the couple's most recent copulation may behave differently during intercourse and thus provide different stimuli before, and at the time of, ejaculation. This may be significant because evidence that ejaculates obtained via uninterrupted coitus have greater semen volume, more total sperm, and greater sperm motility than those obtained via coitus interruptus (Zavos et al., 1994) indicates that sexual stimuli present at the moment of ejaculation may be important determinants of ejaculate composition.

Another problem is the possibility that during periods of partner absence, men may spend more time associating, and perhaps flirting, with women other than their primary partner. Given that sexual arousal immediately before ejacula- 
tion can facilitate sperm delivery and improve semen quality in humans (Pound et al., 2002; Zavos, 1988) and in other species (Almquist, 1973; Almquist, Hale, \& Amann, 1958; Collins, Bratton, \& Hendersen, 1951; Hafs, Kinsey, \& Desjardins, 1962), repeated exposure to arousing stimuli during a period of ejaculatory abstinence could have similar effects. During a period in which a man is away from his partner, these arousing stimuli could be noncopulatory but nevertheless sexually charged encounters with other women.

Finally, changes in semen parameters after a period of partner absence might not function primarily as a response to the risk that a partner contains sperm from a rival male but may be an anticipatory response to the fact that past absence may predict future absence (Gomendio et al., 1998). Thus, increases in the number of sperm delivered might serve to maximize the chances of conception during a future period of partner absence during which ovulation might occur.

\section{Physiological Mechanisms of Prudent Sperm Allocation}

The findings of Baker and Bellis (1993a, 1995) suggest that men may be capable of prudent sperm allocation, but it is not clear how they accomplish this. The physiological mechanisms involved in the regulation of ejaculate composition are poorly understood, but clues as to their possible nature might be derived from observations of the factors known to affect semen parameters.

In studies in which men provide multiple semen specimens over several days or weeks, there is substantial intraindividual variability in parameters such as ejaculate volume and sperm concentration (Mallidis et al., 1991; Read \& Schnieden, 1978; Schwartz et al., 1979), in part because both parameters are affected by the duration of ejaculatory abstinence (e.g., Padova, Tita, Briguglia, \& Giuffrida, 1988; Sauer, Zeffer, Buster, \& Sokol, 1988). There also is evidence that the context in which an ejaculate is produced can be important. For example, ejaculates produced during copulation and collected in nonspermicidal condoms are generally superior to those produced via masturbation (Zavos, 1985). Copulatory ejaculates, relative to masturbatory ejaculates, have greater volumes, more total sperm, and a higher grade of sperm motility (Zavos \& Goodpasture, 1989). The percentage of motile and morphologically normal sperm also is higher in the case of copulatory ejaculates, and these ejaculates consequently perform better on various sperm function tests (Sofikitis \& Miyagawa, 1993).

The mechanisms that cause copulatory ejaculates to contain more sperm than masturbatory ejaculates are not fully understood, but the difference may be attributable, in part, to the greater intensity and duration of sexual arousal that typically precedes copulatory ejaculation. One study indicated that sexual stimulation, in the form of sexually explicit videotapes, can improve semen parameters for masturbatory ejaculates (Yamamoto, Sofikitis, Mio, \& Miyagawa, 2000), but this result contradicts a previous finding (van Roijen et al., 1996). Increases in the duration of precoital stimulation increase the number of motile sperm with normal morphology in copulatory ejaculates (Zavos, 1988), and there also is a positive association between duration of preejaculatory sexual arousal and sperm concentration for masturbatory ejaculates (Pound et al., 2002). Relationships between semen quality and duration of preejaculatory sexual arousal also have been documented in domesticated farm animals when specimens are collected for artificial insemination (e.g., Almquist, 1973; Almquist et al., 1958; Collins et al., 1951; Hafs et al., 1962).

Given the documented relationship between duration of preejaculatory sexual arousal and the number of sperm ejaculated in various species, it is possible that males achieve adaptive changes in ejaculate composition through behavioral changes that prolong arousal before ejaculation. However, the idea that males delay intromission and ejaculation in response to cues of sperm competition risk is somewhat counterintuitive. Sperm competition is a race as well as a lottery, and males might be expected to experience increased sexual motivation at such times because it may be costly to prolong ejaculatory latency and thus delay insemination. Whether the increased number of sperm ejaculated with prolonged arousal has an adaptive function is not clear, but the physiological mechanisms responsible for this increase may be involved in adaptive increases in sperm number under other circumstances. An understanding of how sexual arousal can improve semen quality therefore can shed light on 
some of the possible sites where adaptive regulation might take place.

Sexual arousal increases the rate of sperm transport in the vas deferens (Prins \& Zaneveld, 1979, 1980), and it has been suggested that adaptive regulation of ejaculate composition in response to variations in sperm competition risk might be mediated by changes in vas deferens contractility (Baker \& Bellis, 1995; Pound, 1999). Consistent with this hypothesis is the finding that contractions of this muscular duct may be modulated by hormones whose secretion can be regulated by aspects of the social environment that could be predictive of sperm competition risk (Pound, 1999).

\section{Psychological Mechanisms Associated With Prudent Sperm Allocation}

Males in many nonhuman species are capable of adjusting the number of sperm they inseminate in response to cues of sperm competition risk, and there is some evidence that this is something that men might also be able to do (Baker \& Bellis, 1993a). Little attention has been paid, however, to the psychological mechanisms that might mediate such responses in either human or nonhuman males. Adaptive changes in semen parameters can serve no function unless they are accompanied by a desire to copulate with a partner when cues of sperm competition risk are present. Accordingly, Shackelford et al. (2002) investigated the psychological responses of men to cues of sperm competition risk, arguing that there must be psychological mechanisms in men that evolved to motivate behavior that would have increased the probability of success in sperm competition in ancestral environments.

Baker and Bellis (1993a, 1995) operationalized risk of sperm competition as the proportion of time a couple has spent together since their most recent copulation and examined changes in semen parameters associated with variations in this index, which, they argued, is inversely related to the risk of sperm competition. However, Shackelford et al. (2002) argued that it is probably time spent apart that has most salience to men themselves, and it is this information that is processed by male psychological mechanisms that subsequently motivate a man to inseminate his partner as soon as possible to combat the increased risk of sperm competition.
It is not total time since most recent copulation, but the proportion of time a couple has spent apart since their most recent copulation (time during which a man cannot account for his partner's activities), that is linked to a man's risk that his partner's reproductive tract might contain the sperm of rival males (Baker \& Bellis, 1995). Nevertheless, total time since most recent copulation might have important, and independent, effects on a man's sexual behavior. As total time since most recent copulation increases, a man might feel increasingly "sexually frustrated" whether or not that time has been spent apart or together. To address the potential confound, Shackelford et al. (2002) assessed the relationships between male sexual psychology and behaviors predicted to be linked to the risk of sperm competition (as assessed via proportion of time spent apart since most recent copulation), controlling for total time since a couple's most recent copulation.

Shackelford et al. (2002) suggested that men might respond differently to cues of sperm competition risk depending on the nature of their relationship with a particular woman. Satisfaction with and investment in a relationship are likely to be linked, with the result that a man who is more satisfied may have more to lose in the event of cuckoldry. For this reason, when examining the responses of men to increases in the proportion of time spent apart from their partner since their most recent copulation, Shackelford et al. controlled for the extent to which the participants were satisfied with their relationships.

Consistent with their predictions, Shackelford et al. (2002) found that a man who has spent a greater (relative to a man who has spent a lesser) proportion of time apart from his partner since the couple's most recent copulation (and, therefore, faces a higher risk of sperm competition) rates his partner as more attractive, reports that other men find his partner more attractive, reports greater interest in copulating with his partner, and reports that his partner is more interested in copulating with him. The effects of proportion of time spent apart since the couple's most recent copulation were independent of the total time since their most recent copulation and independent of relationship satisfaction. These findings support the hypothesis that, as is the case with males of other socially monogamous but not sexually exclusive species, men have psychological mechanisms de- 
signed to solve the adaptive problems associated with a partner's sexual infidelity.

\section{Influence of Sperm Competition on Men's Reproductive Anatomy and Copulatory Behavior}

The ability to inseminate a large number of sperm depends on the ability to produce them, and consequently theoretical models (e.g., Parker, 1982, 1990) predict a positive relationship between investment in sperm production and incidence of sperm competition across species. Empirical evidence has confirmed this prediction in various taxa, including primates, in which testis size relative to body weight is correlated positively with incidence of polyandrous mating (Harcourt et al., 1981; Harvey \& Harcourt, 1984; Short, 1979). Smith (1984) argued that the fact that men have testes that are larger relative to body size than those of monandrous species such as the gorilla and orangutan suggests that polyandry was an important selection pressure during human evolution. As Gomendio et al. (1998) noted, however, human relative testis size is closer to these monandrous primates than to the highly polyandrous chimpanzee. Nevertheless, Gomendio et al.'s conclusion that humans are monandrous is not justified. Dichotomizing species into monandrous and polyandrous groups is not useful when there is continuous variation across species in the frequency with which females mate multiply. When degree of polyandry is considered along a continuum, although human males have not experienced levels of sperm competition as high as have been documented in several primate species, it is unlikely that sperm competition was completely absent over human evolutionary history.

Human males have a penis that is longer than that of any other species of ape (Short, 1979), but in relation to body weight it is no longer than the chimpanzee penis (Gomendio et al., 1998). Several arguments have been offered to explain how the length and shape of the human penis might reflect adaptation to an evolutionary history of sperm competition. For example, a long penis may be advantageous in the context of scramble competition, which combines elements of a race and a lottery, because being able to place an ejaculate deep inside the vagina, close to the cervix, may increase the chance of fertilization (Baker \& Bellis, 1995; Short, 1979;
Smith, 1984). In addition, it has been suggested that, analogous to sperm-removing properties of some insect penises (e.g., Waage, 1979), the length, width, and shape of the human penis may have evolved to function as a semen displacement device (Baker \& Bellis, 1995).

Using artificial genitals and simulated semen, Gallup et al. (2003) tested empirically Baker and Bellis's (1995) hypothesis that the human penis is designed to displace semen deposited by other men in the reproductive tract of a woman. Gallup et al. documented that an artificial phallus with a glans and coronal ridge approximating a real human penis displaced significantly more simulated semen than did a phallus lacking these features. When the penis is inserted into the vagina, the frenulum of the coronal ridge makes semen displacement possible by allowing the fluid to flow back under the penis alongside the frenulum and collect on the anterior of the shaft behind the coronal ridge. However, displacement of simulated semen occurred only when a phallus was inserted at least $75 \%$ of its length into the artificial vagina, suggesting that success in displacing rival semen may depend on specific copulatory behaviors. Following allegations of female infidelity or separation from their partners (contexts in which the likelihood of rival semen being present in the reproductive tract is relatively greater), both men and women reported that men thrusted deeper and more quickly at the couple's next copulation (Gallup et al., 2003), behavior likely to increase semen displacement.

In an independent test of the hypothesis that successfully displacing rival semen may require specific copulatory behaviors, Goetz et al. (2005) investigated whether and how men under a high risk of sperm competition might attempt to "correct" a female partner's sexual infidelity. Using a self-report survey, men in committed, sexual relationships reported their use of specific copulatory behaviors arguably designed to displace the semen of rival men. The copulatory behaviors assessed included number of thrusts, deepest thrust, average depth of thrusts, and duration of sexual intercourse. An increase in these behaviors would afford a man a better chance to displace rival semen. As hypothesized, men mated to women who placed them at a high recurrent risk of sperm competition were more likely to perform behaviors that could aid semen displacement, suggesting that men engage in specific copulatory behav- 
iors apparently designed to correct female sexual infidelity by displacing rival semen that may be present in the woman's reproductive tract.

One concern with the hypothesis that the human penis has evolved as a semen displacement device is that, during copulation, the penis would frequently remove a man's own semen, even if the least conservative estimates of the frequency of extrapair copulations are accepted. The consequences of such an effect might be minimized, however, if the temporal spacing between successive in-pair copulations is much greater than the spacing between copulations involving different men. Indeed, the refractory period may have been designed for this purpose, with the inability to maintain an erection after ejaculation functioning to minimize self-semen displacement (Gallup \& Burch, 2004).

\section{Influence of Sperm Competition on Men's Mate Selection}

The selection pressures associated with sperm competition may have led to the evolution of mate preferences in men that function to select, as shortterm sexual partners, women who present the lowest risk of current or future sperm competition (Shackelford, Goetz, LaMunyon, Quintus, \& Weekes-Shackelford, 2004). The risk of sperm competition for a man increases with a prospective short-term partner's involvement in one or more relationships. Women who are not involved in a long-term relationship and do not have casual sexual partners, for example, present a low risk of sperm competition. Consequently, such women may be perceived as desirable short-term sexual partners. Women who are not involved in a longterm relationship but who engage in short-term matings may present a moderate risk of sperm competition, because they probably do not experience difficulty obtaining willing sexual partners. As a result of frequent inseminations by their primary partner, women involved in a long-term relationship may present the highest risk of sperm competition and thus might be least attractive as short-term sexual partners.

As predicted, Shackelford et al. (2004) found that men's reported likelihood of pursuing a short-term sexual relationship was lowest when imagining that the potential short-term partner was married, next lowest when imagining that she was not married but involved in casual sexual relationships, and highest when imagining that she was not married and not involved in any casual sexual relationships. These results suggest that, when selecting short-term sexual partners, men do so in part to avoid sperm competition.

There are, however, a number of possible alternative explanations. First, a man is less likely to experience a potentially violent confrontation with a rival male if he pursues a woman who is not already involved in a relationship. Second, a female who is already involved in a sexual relationship may already be pregnant and thus unable to conceive. Finally, by preferring unmated women, men may avoid the costs associated with contracting a sexually transmitted disease (STD). The data, however, are inconsistent with this alternative explanation. The potential short-term partner most likely to be infected with an STD arguably would be the one having casual sex, who therefore would be least preferred according to this alternative hypothesis. The married potential sexual partner, however, was the least preferred. Thus, men's preferences suggest that avoiding STDs may be less important than avoiding sperm competition when selecting short-term partners.

\section{Influence of Sperm Competition on Men's Sexual Arousal}

Men's sexual fantasies often involve sex with multiple, anonymous partners (Ellis \& Symons, 1990), behavior that would have had fitness payoffs in ancestral environments, that is, the pursuit of numerous, low-investment copulations. It has been suggested, however, that although men might desire and seek sexual variety and the absence of competition with other men, cues of sperm competition risk might nevertheless be sexually arousing. Pound (2002) argued that sexual arousal may be an adaptive response to increased sperm competition risk because it may motivate the pursuit of copulation and thus could lead to the displacement of rival males before they achieve insemination and the delivery of more sperm as a consequence of more frequent intromission. Moreover, sexual arousal may be a psychological correlate or cause of facultative increases in the number of sperm ejaculated.

Pound (2002) hypothesized that men, therefore, should be more aroused by pornography incorporating cues of sperm competition than by comparable material in which such cues are absent. Con- 
tent analyses of pornographic images on World Wide Web sites and of commercial "adult" video releases revealed that depictions of sexual activity involving a female and multiple males are more prevalent than those involving a male and multiple females, indicating that the former category may be preferred by men. In addition, an online survey of self-reported preferences and an online preference study that unobtrusively assessed image selection behavior yielded corroborative results. Pound argued that the most parsimonious explanation for such results is that male arousal in response to visual cues of sperm competition risk reflects the functioning of psychological mechanisms that would have motivated adaptive patterns of copulatory behavior in ancestral males exposed to evidence of female promiscuity.

The idea that men might experience increased sexual motivation in response to cues of sperm competition risk is supported by anecdotal accounts of men who engage in "swinging" or "partner swapping." Encouraging one's partner to copulate with other men appears to be maladaptive in that it increases the risk of cuckoldry. However, it seems that in certain contemporary societies some men do just this, perhaps because such men often report that they find the sight of their partner interacting sexually with other men to be sexually arousing (Talese, 1981). Moreover, they report that they experience increased sexual desire for their partner following her sexual encounters with other men, and some indicate that this increase in desire is particularly acute when they have witnessed their partner having sexual intercourse with another man (T. Gould, 1999).

\section{Is There Evidence of Contest Competition Between Men's Ejaculates?}

Apart from the remarkable feat of traversing a hostile reproductive tract to fertilize an ovum, sperm do some astonishing things. Sperm of the common wood mouse (Apodemus sylvaticus), for example, have a hook that allows the sperm to adhere to one another and form a motile "train" of several thousand sperm (Moore, Dvorakova, Jenkins, \& Breed, 2002). These trains display greater motility and velocity than single sperm, facilitating fertilization. This cooperative behavior between sperm of a single male reveals that sperm are capable of complex behavior. Might mammalian sperm display equally complex behavior in the presence of rival sperm?

Baker and Bellis (1988) proposed that, in mammals, postcopulatory competition between rival male ejaculates might involve more than simply scramble competition and that rival sperm may interfere actively with each other's ability to fertilize ova. Mammalian ejaculates contain sperm that are polymorphic (i.e., existing in different morphologies or shapes and sizes). Previously interpreted as the result of developmental error (Cohen, 1973), Baker and Bellis suggested that sperm polymorphism was not due to meiotic errors but instead reflected a functionally adaptive "division of labor" between sperm. They proposed two categories of sperm: "egg-getters" and "kamikaze" sperm. Egg-getters, they argued, represent the small proportion of sperm programmed to fertilize ova, whereas most of the ejaculate is composed of kamikaze sperm that function to prevent other males' sperm from fertilizing ova by forming a barrier at strategic positions within the reproductive tract. Preliminary evidence for the "kamikaze sperm hypothesis" came from the observation that copulatory plugs in bats are composed of so-called "malformed" sperm (Fenton, 1984) and from documentation that, in laboratory mice, different proportions of sperm morphs are found reliably at particular positions within the female reproductive tract (Cohen, 1977).

Harcourt (1989), however, pointed out a number of problems with Baker and Bellis's (1988) suggestion that "deformed" sperm are specialized to block the progression of rival sperm. For example, although deformed sperm can be found in copulatory plugs (e.g., Fenton, 1984), there is no evidence that they are required for plug formation. Plugs are generally formed from coagulating seminal fluids, and deformed sperm might simply become trapped in them. Harcourt also noted that, in lions, inbreeding results in an increase in the proportion of deformed sperm (Wildt et al., 1987) and suggested that this is the opposite of what might be expected if deformed sperm were an adaptive trait. Moreover, he argued that, across primate species, the absence of a positive relationship between the incidence of polyandry and the proportion of deformed sperm in ejaculates suggests that deformed sperm do not have an adaptive function related to sperm competition. Following Cohen (1973), Harcourt (1989, p. 864) 
concluded that "abnormal sperm are still best explained by errors in production."

Baker and Bellis (1989a) responded to Harcourt's (1989) objections and elaborated on the kamikaze sperm hypothesis, proposing a more active role for kamikaze sperm. At the same time, however, they "moved the goal posts" (Birkhead, Moore, \& Bedford, 1997) to a certain extent by suggesting that kamikaze sperm might, in fact, appear morphologically normal. They speculated that evolutionary arms races between ejaculates could result in kamikaze sperm that incapacitate rival sperm with acrosomal enzymes or by inducing attack by female leukocytes. Baker and Bellis (1995) later suggested that, in addition to sperm specialized to "seek and destroy" rival sperm, there also may be another type of kamikaze sperm that act as "blockers" that inhibit rival sperm progression.

In a test of the hypothesis, Baker and Bellis (1995, p. 274) reported that, when ejaculates from two different men were mixed in vitro, there was increased agglutination, reduced sperm velocity, and increased sperm mortality relative to homospermic control mixtures. They interpreted these findings as an indication that, when encountering sperm from another male, some sperm (blockers) impede the progress of rival sperm and some (seek-and-destroyers) attack and incapacitate rival sperm. The kamikaze sperm hypothesis and the reported interaction of rival sperm have generated substantial criticism, however (see, e.g., Birkhead et al., 1997; Short, 1998).

Moore, Martin, and Birkhead (1999) attempted to replicate the finding that sperm from different males incapacitate each other in a variety of ways, but they did not identify significant increases in aggregation or mortality, or significant decreases in velocity, in heterospermic versus homospermic mixtures. It should be noted, however, that whereas Moore et al. looked for incapacitation effects after incubating heterospermic mixtures for up to $3 \mathrm{hr}$, Baker and Bellis (1995) reported increased sperm mortality and decreased velocity occurring 3 to 6 hours after mixing. Moore et al. offered theoretical reasons for the shorter interactive window (i.e., because 1 to $3 \mathrm{hr}$ is the time that sperm normally remain in the human vagina), but perhaps this interval was too short. Upon insemination, sperm have one of two initial fates: Some are ejected from the vagina, and some travel quickly from the vagina to the cer- vix and uterus. Perhaps most sperm warfare takes place around the cervix and in the uterus, locations in the reproductive tract where sperm are able to interact for a prolonged period. If this is the case, Baker and Bellis's longer, 3- to 6-hr interactive window would be more valid ecologically. In addition, both Baker and Bellis and Moore et al. investigated sperm interactions in vitro, and sperm may behave differently in vivo.

Aside from Moore et al.'s (1999) failure to replicate Baker and Bellis's (1995) findings, additional skepticism is generated by Baker and Bellis's failure to clearly specify how sperm can differentiate self-sperm from non-self-sperm. Given that sperm consist of a diminutive singlecell structure, a self-recognition system that must differentiate between not only different genes (because even sperm from a single male contain different combinations of genes) but different sets of competing genes (i.e., genes from another male) may be unlikely to have evolved. Moore et al.'s failure to replicate Baker and Bellis's findings and the absence of a clear self-recognition system are not fatal to the kamikaze sperm hypothesis, but such concerns are cause for skepticism about its plausibility. More work remains before clear conclusions can be drawn about the status of the hypothesis. However, supporters of the hypothesis may be encouraged by recent work conducted by Kura and Nakashima (2000), who used mathematical models to identify the conditions necessary for soldier sperm classes to evolve and concluded that such conditions are not stringent and far from unlikely.

\section{Women's Adaptations to Sperm Competition}

If sperm competition was a recurrent feature of human evolutionary history, adaptations should be expected not only in men but also in women. Evidence of postcopulatory sperm selection by females is scarce across species, but it has been shown, for example, that female feral fowl actively eject sperm from lower ranking males (Pizzari \& Birkhead, 2000). Similarly, it is possible that women are not passive sperm receptacles but may be able to influence the outcome of any sperm competition that takes place within their reproductive tracts. In principle, female influence may be exerted before, during, and after copulation. Female 
choice that precedes copulation is known as "precopulatory female choice," whereas "postcopulatory female choice" refers to female influence that follows initiation of copulation (see Eberhard, 1996). An evolutionary history of sperm competition is expected to have produced precopulatory and postcopulatory female adaptations.

\section{Precopulatory Female Choice: Promoting and Avoiding Sperm Competition}

Bellis and Baker (1990) documented that women are more likely to engage in successive copulations with in-pair and extrapair partners in a short time interval when the probability of conception is highest, suggesting that women may have psychological adaptations that motivate active promotion of sperm competition, thus allowing their egg(s) to be fertilized by the most competitive sperm. It is possible that human female psychology also includes mechanisms designed to motivate, under certain conditions, the avoidance of sperm competition. Gangestad, Thornhill, and Garver (2002), for example, documented that as women enter the high conception risk phase of their menstrual cycle, they are sexually attracted to, and fantasize about, men other than their in-pair partner (but see Pillsworth, Haselton, \& Buss, 2004). These results suggest that women may be able to modulate their sexual activity in such a way as to favor the genes of an extrapair partner over a primary partner by copulating with only the extrapair partner when the likelihood of conception is high. Thus, women's sexual attraction to and fantasies about men other than their in-pair partner may qualify as a precopulatory female adaptation. But because men, in turn, may have been selected to be sensitive to their partner's increased interest in extrapair copulation near ovulation (Gangestad et al., 2002), women may have postcopulatory adaptations designed to selectively favor sperm from one man over another.

\section{Postcopulatory Female Choice: A Function for Female Coital Orgasm?}

One such postcopulatory adaptation in women may be orgasm. Because the structure that devel- ops into a clitoris or a penis is a bipotential organ in a developing embryo, Symons (1979) and S. J. Gould (1987) argued that female orgasm is a by-product of male orgasm. Others have hypothesized, however, that female orgasm has an adaptive function (e.g., Alexander, 1979; Baker \& Bellis, 1993b; Hrdy, 1981; Smith, 1984). A leading functional hypothesis is that female coital orgasm was designed in the context of sperm competition as a mechanism of selective sperm retention (Baker \& Bellis, 1993b; Smith, 1984). Female orgasm causes the cervix to dip into the seminal pool deposited by the male at the upper end of the vagina, and this may result in the retention of greater numbers of sperm (see research reviewed by Baker \& Bellis, 1993b, 1995). Baker and Bellis (1993b) and Smith (1984) contended that, through strategic coital orgasm, women may select preferentially the sperm of extrapair partners who are likely to be of higher genetic quality than in-pair partners.

In a test of this hypothesis, Baker and Bellis (1993b) estimated the number of sperm retained in the female reproductive tract after copulation by examining vaginal "flowbacks" (i.e., seminal and vagina fluids ejected after copulation). They reported that women influence the number of sperm retained in their reproductive tract through the presence and timing of a coital orgasm. Specifically, coital orgasms that occurred between 1 min before and 45 min after their partner ejaculated led to significantly greater sperm retention than coital orgasms that occurred more than $1 \mathrm{~min}$ before or more than 45 min after their partner ejaculated. Analyzing women's copulatory behavior, Baker and Bellis also provided evidence that women with an in-pair partner and one or more extrapair partners had significantly fewer high sperm retention orgasms with their in-pair partner and more high sperm retention orgasms with their extrapair partners.

Missing from Baker and Bellis's (1993b) study, however, was an explicit demonstration of higher sperm retention by women when copulating with partners of higher genetic quality. Thornhill, Gangestad, and Comer (1995), however, documented that women mated to men with low fluctuating asymmetry (indicating relatively high genetic quality) reported significantly more copulatory orgasms than did women mated to men with high fluctuating asymmetry (indicating relatively low genetic quality). Women mated to men with low fluc- 
tuating asymmetry did not simply have more orgasms but specifically reported more copulatory orgasms likely to result in greater sperm retention. Another indicator of high genetic quality exhibiting a relationship to fluctuating asymmetry is physical attractiveness. Replicating Thornhill et al.'s work, Shackelford et al. (2000) found that women mated to more physically attractive men were more likely to report having a copulatory orgasm at their most recent copulation than were women mated to less attractive men.

Although the hypothesis that female orgasm is an adaptation for postcopulatory female choice between rival ejaculates is plausible, the functional significance of the female orgasm is still hypothetical (Pound \& Daly, 2000). Baker and Bellis (1995) simply inferred, from differences in the size of sperm flowbacks, that women retain more sperm if they orgasm after their partner ejaculates than if they orgasm earlier. However, differences in flowback size may have been due to differences in the size of the initial ejaculates rather than differential sperm retention (Pound \& Daly, 2000). Whether or not a female has an orgasm before or after her partner is confounded with the duration of male preejaculatory sexual arousal, a factor shown to be correlated positively with the number of sperm ejaculated (Pound et al., 2002; Zavos, 1988). Ejaculations that occur before female orgasm are likely to be associated with shorter durations of preejaculatory male sexual arousal than those that occur after and thus may contain fewer sperm, which could account for the smaller flowbacks seen in the former condition.

Perhaps most important for theories about the functional significance of the human female orgasm, it has yet to be demonstrated that female orgasm influences conception rates. If female orgasm causes the cervix to dip into the seminal pool, resulting in greater numbers of sperm being retained, it would follow that the likelihood of conception will increase accordingly, but this has not been demonstrated empirically. The observation that men are sometimes concerned with whether their partner achieves orgasm and the observation that women often fake orgasm to appease their partner further suggest that female orgasm may have adaptive value (see Thornhill et al., 1995).

For internal fertilizers, male success in sperm competition depends on what happens within the female reproductive tract. Consequently, fe- male adaptations that influence the outcome of sperm competition should be expected. However, direct evidence of preferential use of sperm by females is scarce across all taxa and altogether absent in humans, primarily because it is methodologically difficult to study mechanisms of female influence on fertilization success within the female reproductive tract. In some nonhuman animals, preferential use of sperm can be studied by examination of genetic markers or sperm storage organs in females (see, e.g., Eberhard, 1996).

Intersexual conflict between ancestral males and females produces a coevolutionary arms race between the sexes in which an advantage gained by one sex selects for counteradaptations in the other sex (see, e.g., Rice, 1996). Thus, it is to be expected that adaptations to sperm competition in men are likely to be met by counteradaptations in women. However, given the methodological difficulties associated with studying female influences on sperm competition, it is not surprising that there has been less work examining possible adaptations to sperm competition in women than in men. The fact that the bulk of this article has focused on possible male adaptations is a reflection of the historical and current state of theory and research in the field.

\section{Concluding Remarks}

Sperm competition was first identified as a mode of postcopulatory competition between males by Geoff Parker in the 1970s. Since then, evolutionary biologists and behavioral ecologists have described many anatomical, physiological, and behavioral adaptations to sperm competition in both males and females of various nonhuman species. The question as to whether sperm competition has been an important selection pressure during human evolution remains controversial, and further research is needed to establish the extent to which this might be the case. However, as outlined in this article, there is now some evidence to suggest that an evolutionary history of sperm competition may have influenced sexual behavior, reproductive physiology, and anatomy in both sexes.

It now seems unlikely that sperm from rival men actively interfere with each other's attempts to reach and fertilize ova within women's reproductive tracts. However, men may 
nevertheless be capable of prudent sperm allocation in response to variations in sperm competition risk. There are some methodological problems with reports of adaptive ejaculate adjustments by men, but more recent work suggests that aspects of male sexuality such as attraction to and sexual interest in partners, copulatory behaviors, short-term mating preferences, and sources of sexual arousal may reflect adaptations to sperm competition. There are significant problems with some of this work, but this should not discourage researchers from testing predictions about human behavior and reproductive physiology derived from sperm competition theory.

\section{References}

Alexander, R. D. (1979). Sexuality and sociality in humans and other primates. In A. Katchadourian (Ed.), Human sexuality (pp. 81-97). Berkeley: University of California Press.

Almquist, J. O. (1973). Effects of sexual preparation on sperm output, semen characteristics and sexual activity of beef bulls with a comparison to dairy bulls. Journal of Animal Science, 36, 331-336.

Almquist, J. O., Hale, E. B., \& Amann, R. P. (1958). Sperm production and fertility of dairy bulls at high collection frequencies with varying degrees of sexual preparation. Journal of Dairy Science, 41, 733.

Ambriz, D., Rosales, A. M., Sotelo, R., Mora, J. A., Rosado, A., \& Garcia, A. R. (2002). Changes in the quality of rabbit semen in 14 consecutive ejaculates obtained every 15 minutes. Archives of Andrology, 48, 389-395.

Andersson, M. (1994). Sexual selection. Princeton, NJ: Princeton University Press.

Arndt, W. B., Jr., Foehl, J. C., \& Good, F. E. (1985). Specific sexual fantasy themes: A multidimensional study. Journal of Personality and Social Psychology, 48, 472-480.

Baker, R. R., \& Bellis, M. A. (1988). "Kamikaze" sperm in mammals? Animal Behaviour, 36, 936939.

Baker, R. R., \& Bellis, M. A. (1989a). Elaboration of the kamikaze sperm hypothesis: A reply to Harcourt. Animal Behaviour, 37, 865-867.

Baker, R. R., \& Bellis, M. A. (1989b). Number of sperm in human ejaculates varies in accordance with sperm competition theory. Animal Behaviour, 37, 867-869.

Baker, R. R., \& Bellis, M. A. (1993a). Human sperm competition: Ejaculate adjustment by males and the function of masturbation. Animal Behaviour, 46, 861-885.
Baker, R. R., \& Bellis, M. A. (1993b). Human sperm competition: Ejaculate manipulation by females and a function for the female orgasm. Animal Behaviour, 46, 887-909.

Baker, R. R., \& Bellis, M. A. (1995). Human sperm competition. London: Chapman \& Hall.

Baur, B. (1998). Sperm competition in molluscs. In T. R. Birkhead \& A. P. Møller (Eds.), Sperm competition and sexual selection (pp. 255-305). San Diego, CA: Academic Press.

Bellis, M. A., \& Baker, R. R. (1990). Do females promote sperm competition: Data for humans. Animal Behavior, 40, 197-199.

Bellis, M. A., Baker, R. R., \& Gage, M. J. G. (1990). Variation in rat ejaculates consistent with the kamikaze sperm hypothesis. Journal of Mammalogy, 71, 479-480.

Birkhead, T. R., \& Møller, A. P. (1992). Sperm competition in birds. London: Academic Press.

Birkhead, T. R., Moore, H. D. M., \& Bedford, J. M. (1997). Sex, science, and sensationalism. Trends in Ecology and Evolution, 12, 121-122.

Buss, D. M. (2000). The dangerous passion. New York: Free Press.

Buss, D. M. (2004). The evolution of desire (2nd ed.). New York: Basic Books.

Buss, D. M., Larsen, R. J., Westen, D., \& Semmelroth, J. (1992). Sex differences in jealousy: Evolution, physiology and psychology. Psychological Science, 3, 251-255.

Buss, D. M., \& Schmitt, D. P. (1993). Sexual strategies theory: An evolutionary perspective on human mating. Psychological Review, 100, 204-232.

Cohen, J. (1973). Cross-overs, sperm redundancy and their close association. Heredity, 31, 408-413.

Cohen, J. (1977). Reproduction. London: Butterworth.

Collins, W. J., Bratton, R. W., \& Henderson, C. R. (1951). The relationship of semen production to sexual excitement of dairy bulls. Journal of Dairy Science, 34, 224-227.

Cook, P. A., \& Wedell, N. (1996). Ejaculate dynamics in butterflies: A strategy for maximizing fertilization success? Proceedings of the Royal Society of London, B, 263, 1047-1051.

Daly, M., \& Wilson, M. (1980). Discriminative parental solicitude: A biological perspective. Journal of Marriage and the Family, 42, 277-288.

Daly, M., \& Wilson, M. (1982). Whom are newborn babies said to resemble? Ethology and Sociobiology, 3, 69-78.

Daly, M., \& Wilson, M. (1995). Discriminative parental solicitude and the relevance of evolutionary models to the analysis of motivational systems. In M. Gazzaniga (Ed.), The cognitive neurosciences (pp. 1269-1286). Cambridge, MA: MIT Press.

Daly, M., Wilson, M., \& Weghorst, J. (1982). Male sexual jealousy. Ethology and Sociobiology, 3, 1127. 
Darwin, C. (1871). The descent of man and selection in relation to sex. London: Murray.

DelBarco-Trillo, J., \& Ferkin, M. H. (2004). Male mammals respond to a risk of sperm competition conveyed by odours of conspecific males. Nature, 431, 446-449.

Dewsbury, D. A. (1982). Ejaculate cost and male choice. American Naturalist, 119, 601-610.

Dixson, A. F. (1998). Primate sexuality. New York: Oxford University Press.

Eberhard, W. G. (1996). Female control. Princeton, NJ: Princeton University Press.

Ellis, B. J., \& Symons, D. (1990). Sex differences in sexual fantasy: An evolutionary psychological approach. Journal of Sex Research, 27, 527-555.

Fenton, M. B. (1984). The case of vepertilionid and rhinolophid bats. In R. L. Smith (Ed.), Sperm competition and the evolution of animal mating systems (pp. 573-587). London: Academic Press.

Gage, A. R., \& Barnard, C. J. (1996). Male crickets increase sperm number in relation to competition and female size. Behavioral Ecology and Sociobiology, 38, 349-353.

Gage, M. J. G. (1991). Risk of sperm competition directly affects ejaculate size in the Mediterranean fruit fly. Animal Behaviour, 42, 1036-1037.

Gage, M. J. G. (1994). Associations between bodysize, mating pattern, testis size and sperm lengths across butterflies. Proceedings of the Royal Society of London, B, 258, 247-254.

Gage, M. J. G., \& Baker, R. R. (1991). Ejaculate size varies with sociosexual situation in an insect. Ecological Entomology, 16, 331-337.

Gallup, G. G., \& Burch, R. L. (2004). Semen displacement as a sperm competition strategy in humans. Evolutionary Psychology, 2, 12-23.

Gallup, G. G., Burch, R. L., Zappieri, M. L., Parvez, R. A., Stockwell, M. L., \& Davis, J. A. (2003). The human penis as a semen displacement device. Evolution and Human Behavior, 24, 277-289.

Gangestad, S. W., \& Simpson, J. A. (2000). The evolution of human mating: Trade-offs and strategic pluralism. Behavioral and Brain Sciences, 23, 573-587.

Gangestad, S. W., Thornhill, R., \& Garver, C. E. (2002). Changes in women's sexual interests and their partner's mate-retention tactics across the menstrual cycle: Evidence for shifting conflicts of interest. Proceedings of the Royal Society of London, 269, 975-982.

Ginsberg, J. R., \& Rubenstein, D. I. (1990). Sperm competition and variation in zebra mating behavior. Behavioral Ecology and Sociobiology, 26, 427-434

Goetz, A. T., Shackelford, T. K., Weekes-Shackelford, V. A., Euler, H. A., Hoier, S., Schmitt, D. P., \& LaMunyon, C. W. (2005). Mate retention, semen displacement, and human sperm competition: A preliminary investigation of tactics to prevent and correct female infidelity. Personality and Individual Differences, 38, 749-763.

Gomendio, M., Harcourt, A. H., \& Roldán, E. R. S. (1998). Sperm competition in mammals. In T. R. Birkhead \& A. P. Møller (Eds.), Sperm competition and sexual selection (pp. 667-756). New York: Academic Press.

Gomendio, M., \& Roldán, E. R. S. (1993). Mechanisms of sperm competition: Linking physiology and behavioral ecology. Trends in Ecology and Evolution, 8, 95-100.

Gould, S. J. (1987). Freudian slip. Natural History, 96, 14-21.

Gould, T. (1999). The lifestyle. New York: Firefly.

Greiling, H., \& Buss, D. M. (2000). Women's sexual strategies: The hidden dimension of extra-pair mating. Personality and Individual Differences, 28, 929-963.

Hafs, H. D., Kinsey, R. C., \& Desjardins, C. (1962). Sperm output of dairy bulls with varying degrees of sexual preparation. Journal of Dairy Science, 45, 788-793.

Harcourt, A. H. (1989). Deformed sperm are probably not adaptive. Animal Behaviour, 37, 863-865.

Harcourt, A. H., Harvey, P. H., Larson, S. G., \& Short, R. V. (1981). Testis weight, body weight, and breeding system in primates. Nature, 293, 55-57.

Harvey, P. H., \& Harcourt, A. H. (1984). Sperm competition, testis size, and breeding systems in primates. In R. L. Smith (Ed.), Sperm competition and the evolution of animal mating systems (pp. 589-600). San Diego, CA: Academic Press.

Hosken, D. J., \& Ward, P. I. (2001). Experimental evidence for testis size evolution via sperm competition. Ecology Letters, 4, 10-13.

Hrdy, S. B. (1981). The woman that never evolved. Cambridge, MA: Harvard University Press.

Hunt, M. (1974). Sexual behavior in the 70s. Chicago: Playboy Press.

Jennions, M. D., \& Passmore, N. I. (1993). Sperm competition in frogs: Testis size and a sterile male experiment on Chiromantis-xerampelina (Rhacophoridae). Biological Journal of the Linnean Society, 50, 211-220.

Jennions, M. D., \& Petrie, M. (2000). Why do females mate multiply? A review of the genetic benefits. Biological Reviews, 75, 21-64.

Johnson, A. M., Mercer, C. H., Erens, B., Copas, A. J., McManus, S., Wellings, K., et al. (2001). Sexual behaviour in Britain: Partnerships, practices, and HIV risk behaviours. Lancet, 358, 18351842 .

Kura, T., \& Nakashima, Y. (2000). Conditions for the evolution of soldier sperm classes. Evolution, 54, 72-80.

Laumann, E. O., Gagnon, J. H., Michael, R. T., \& Michaels, S. (1994). The social organization of sexuality. Chicago: University of Chicago Press. 
Leitenberg, H., \& Henning, K. (1995). Sexual fantasy. Psychological Bulletin, 117, 469-496.

Mallidis, C., Howard, E. J., \& Baker, H. W. G. (1991). Variation of semen quality in normal men. International Journal of Andrology, 14, 99-107.

Marconato, A., \& Shapiro, D. Y. (1996). Sperm allocation, sperm production and fertilization rates in the bucktooth parrotfish. Animal Behaviour, 52, 971-980.

Møller, A. P. (1985). Mixed reproductive strategy and mate guarding in a semi-colonial passerine, the swallow Hirundo rustica. Behavioral Ecology and Sociobiology, 17, 401-408.

Møller, A. P. (1987). Mate guarding in the swallow Hirundo rustica. Behavioral Ecology and Sociobiology, 21, 119-123.

Møller, A. P. (1988a). Paternity and paternal care in the swallow, Hirundo rustica. Animal Behaviour, 36, 996-1005.

Møller, A. P. (1988b). Testes size, ejaculate quality and sperm competition in birds. Biological Journal of the Linnean Society, 33, 273-283.

Moore, H. D., Dvorakova, K., Jenkins, N., \& Breed, W. (2002). Exceptional sperm cooperation in the wood mouse. Nature, 418, 174-177.

Moore, H. D., Martin, M., \& Birkhead, T. R. (1999). No evidence for killer sperm or other selective interactions between human spermatozoa in ejaculates of different males in vitro. Proceedings of the Royal Society of London, B, 266, 2343-2350.

Nakatsuru, K., \& Kramer, D. L. (1982, May 14). Is sperm cheap: Male fertility and female choice in the lemon tetra (Pisces characidae). Science, 216, 753-755.

Olsson, M., Madsen, T., \& Shine, R. (1997). Sperm really so cheap? Costs of reproduction in male adders, Vipera berus. Proceedings of the Royal Society of London, B, 264, 455-459.

Padova, G., Tita, P., Briguglia, G., \& Giuffrida, D. (1988). Influence of abstinence length on ejaculate characteristics. Acta Europaea Fertilitatis, 19, 29 31.

Parker, G. A. (1970). Sperm competition and its evolutionary consequences in the insects. Biological Reviews, 45, 525-567.

Parker, G. A. (1982). Why are there so many tiny sperm? Sperm competition and the maintenance of two sexes. Journal of Theoretical Biology, 96, 281-294.

Parker, G. A. (1990). Sperm competition games: Raffles and roles. Proceedings of the Royal Society of London, B, 242, 120-126.

Parker, G. A. (1998). Sperm competition and the evolution of ejaculates: Towards a theory base. In T. R. Birkhead \& A. P. Møller (Eds.), Sperm competition and sexual selection (pp. 3-54). New York: Academic Press.

Parker, G. A., Ball, M. A., Stockley, P., \& Gage, M. J. G. (1997). Sperm competition games: A prospective analysis of risk assessment. Proceedings of the Royal Society of London, B, 264, 17931802.

Pelletier, L. A., \& Herold, E. S. (1988). The relationship of age, sex guilt, and sexual experience with female sexual fantasies. Journal of Sex Research, 24, 250-256.

Person, E. S., Terestman, N., Myers, W. A., Goldberg, E. L., \& Salvadori, C. (1989). Gender differences in sexual behaviors and fantasies in a college population. Journal of Sex and Marital Therapy, 15, 187-198.

Pillsworth, E. G., Haselton, M. G., \& Buss, D. M. (2004). Ovulatory shifts in female sexual desire. Journal of Sex Research, 41, 55-65.

Pizzari, T., \& Birkhead, T. R. (2000). Female feral fowl eject sperm of subdominant males. Nature, 405, 787-789.

Platek, S. M. (2003). Effects of paternal resemblance on paternal investment: An evolutionary model. Evolution and Cognition, 9, 189-197.

Pound, N. (1999). Effects of morphine on electrically evoked contractions of the vas deferens in two congeneric rodent species differing in sperm competition intensity. Proceedings of the Royal Society of London, B, 266, 1755-1858.

Pound, N. (2002). Male interest in visual cues of sperm competition risk. Evolution and Human Behavior, 23, 443-466.

Pound, N., \& Daly, M. (2000). Functional significance of human female orgasm still hypothetical. Behavioral and Brain Sciences, 23, 620-621.

Pound, N., \& Gage, M. J. G. (2004). Prudent sperm allocation in Rattus norvegicus: A mammalian model of adaptive ejaculate adjustment. Animal Behaviour, 68, 819-823.

Pound, N., Javed, M. H., Ruberto, C., Shaikh, M. A., \& Del Valle, A. P. (2002). Duration of sexual arousal predicts semen parameters for masturbatory ejaculates. Physiology and Behavior, 76, 685689.

Preston, B. T., Stevenson, I. R., Pemberton, J. M., \& Wilson, K. (2001). Dominant rams lose out by sperm depletion. Nature, 409, 681-682.

Price, J. H., \& Miller, P. A. (1984). Sexual fantasies of Black and of White college students. Psychological Reports, 54, 1007-1014.

Prins, G. S., \& Zaneveld, L. J. (1979). Distribution of spermatozoa in the rabbit vas deferens. Biology of Reproduction, 21, 181-185.

Prins, G. S., \& Zaneveld, L. J. (1980). Radiographic study of fluid transport in the rabbit vas deferens during sexual rest and after sexual activity. Journal of Reproduction and Fertility, 58, 311-319.

Read, M. D., \& Schnieden, H. (1978). Variations in sperm count in oligozoospermic or asthenozoospermic patients. Andrologia, 10, 52-55. 
Rice, W. R. (1996). Sexually antagonistic male adaptation triggered by experimental arrest of female evolution. Nature, 381, 232-234.

Rokach, A. (1990). Content analysis of sexual fantasies of males and females. Journal of Psychology, 124, 427-436.

Sauer, M. V., Zeffer, K. B., Buster, J. E., \& Sokol, R. Z. (1988). Effect of abstinence on sperm motility in normal men. American Journal of Obstetrics and Gynecology, 158, 604-607.

Schmitt, D. P., Alcalay, L., Allik, J., Ault, L., Austers, I., \& Bennett, K. L. (2003). Universal sex differences in the desire for sexual variety: Tests from 52 nations, 6 continents, and 13 islands. Journal of Personality and Social Psychology, 85, 85-104.

Schmitt, D. P., Shackelford, T. K., \& Buss, D. M. (2001). Are men really more oriented toward short-term mating than women?: A critical review of theory and research. Psychology, Evolution, and Gender, 3, 211-239.

Schmitt, D. P., Shackelford, T. K., Duntley, J., Tooke, W., \& Buss, D. M. (2001). The desire for sexual variety as a tool for understanding basic human mating strategies. Personal Relationships, 8, 425-455.

Schwartz, D., Laplanche, A., Jouannet, P., \& David, G. (1979). Within-subject variability of human semen in regard to sperm count, volume, total number of spermatozoa and length of abstinence. Journal of Reproduction and Fertility, 57, 391-395.

Shackelford, T. K. (2003). Preventing, correcting, and anticipating female infidelity: Three adaptive problems of sperm competition. Evolution and Cognition, 9, 90-96.

Shackelford, T. K., Goetz, A. T., LaMunyon, C. W., Quintus, B. J., \& Weekes-Shackelford, V. A. (2004). Sex differences in sexual psychology produce sex similar preferences for a short-term mate. Archives of Sexual Behavior, 33, 405-412.

Shackelford, T. K., \& LeBlanc, G. J. (2001). Sperm competition in insects, birds, and humans: Insights from a comparative evolutionary perspective. Evolution and Cognition, 7, 194-202.

Shackelford, T. K., LeBlanc, G. J., Weekes-Shackelford, V. A., Bleske-Rechek, A. L., Euler, H. A., \& Hoier, S. (2002). Psychological adaptation to human sperm competition. Evolution and Human Behavior, 23, 123-138.

Shackelford, T. K., Weekes-Shackelford, V. A., LeBlanc, G. J., Bleske, A. L., Euler, H. A., \& Hoier, S. (2000). Female coital orgasm and male attractiveness. Human Nature, 11, 299-306.

Shapiro, D. Y., Marconato, A., \& Yoshikawa, T. (1994). Sperm economy in a coral reef fish, Thalassoma bifasciatum. Ecology, 75, 1334-1344.

Short, R. V. (1979). Sexual selection and its component parts, somatic and genital selection as illus- trated by man and the great apes. Advances in the Study of Behavior, 9, 131-158.

Short, R. V. (1981). Sexual selection in man and the great apes. In C. E. Graham (Ed.), Reproductive biology of the great apes (pp. 319-341). New York: Academic Press.

Short, R. V. (1998). Review of Human sperm competition: Copulation, masturbation and infidelity, by R. R. Baker and M. A. Bellis. European Sociobiology Society Newsletter, 47, 20-23.

Simmons, L. W. (2001). Sperm competition and its evolutionary consequences in the insects. Princeton, NJ: Princeton University Press.

Smith, R. L. (1984). Human sperm competition. In R. L. Smith (Ed.), Sperm competition and the evolution of animal mating systems (pp. 601-660). New York: Academic Press.

Sofikitis, N. V., \& Miyagawa, I. (1993). Endocrinological, biophysical, and biochemical parameters of semen collected via masturbation versus sexual intercourse. Journal of Andrology, 14, 366-373.

Symons, D. (1979). The evolution of human sexuality. New York: Oxford University Press.

Talese, G. (1981). Thy neighbor's wife. New York: Ballantine Books.

Thornhill, R. (1983). Cryptic female choice and its implications in the scorpionfly Harpobittacus nigriceps. American Naturalist, 122, 765-788.

Thornhill, R., Gangestad, S. W., \& Comer, R. (1995). Human female orgasm and mate fluctuating asymmetry. Animal Behaviour, 50, 1601-1615.

Trivers, R. L. (1972). Parental investment and sexual selection. In B. Campbell (Ed.), Sexual selection and the descent of man (pp. 139-179). London: Aldine.

van Roijen, J. H., Slob, A. K., Gianotten, W. L., Dohle, G. R., vander Zon, A. T. M., Vreeburg, T. M., \& Weber, R. F. A. (1996). Sexual arousal and the quality of semen produced by masturbation. Human Reproduction, 11, 147-151.

Waage, J. K. (1979, March 2). Dual function of the damselfly penis: Sperm removal and transfer. Science, 203, 916-918.

Wedell, N., Gage, M. J. G., \& Parker, G. A. (2002). Sperm competition, male prudence and sperm-limited females. Trends in Ecology and Evolution, 17, 313-320.

Wildt, D. E., Bush, M., Goodrowe, K. L., Packer, C., Pusey, A. E., Brown, J. L., et al. (1987). Reproductive and genetic consequences of founding isolated lion populations. Nature, 329, 328-331.

Wilson, G. D. (1987). Male-female differences in sexual activity, enjoyment and fantasies. Personality and Individual Differences, 8, 125-127.

Wilson, G. D. (1997). Gender differences in sexual fantasy: An evolutionary analysis. Personality and Individual Differences, 22, 27-31. 
Wilson, G. D., \& Lang, R. J. (1981). Sex differences in sexual fantasy patterns. Personality and Individual Differences, 2, 343-346.

Wilson, M., \& Daly, M. (1992). The man who mistook his wife for a chattel. In J. H. Barkow, L. Cosmides, \& J. Tooby (Eds.), The adapted mind (pp. 19-136). New York: Oxford University Press.

Wyckoff, G. J., Wang, W., \& Wu, C. (2000). Rapid evolution of male reproductive genes in the descent of man. Nature, 403, 304-308.

Yamamoto, Y., Sofikitis, N., Mio, Y., \& Miyagawa, I. (2000). Influence of sexual stimulation on sperm parameters in semen samples collected via masturbation from normozoospermic men or cryptozoospermic men participating in an assisted reproduction programme. Andrologia, 32, 131-138.

Zavos, P. M. (1985). Seminal parameters of ejaculates collected from oligospermic and normospermic patients via masturbation and at intercourse with the use of a Silastic seminal fluid collection device. Fertility and Sterility, 44, 517-520.
Zavos, P. M. (1988). Seminal parameters of ejaculates collected at intercourse with the use of a seminal collection device with different levels of precoital stimulation. Journal of Andrology, 9, P36.

Zavos, P. M., \& Goodpasture, J. C. (1989). Clinical improvements of specific seminal deficiencies via intercourse with a seminal collection device versus masturbation. Fertility and Sterility, 51, 190-193.

Zavos, P. M., Kofinas, G. D., Sofikitis, N. V., Zarmakoupis, P. N., \& Miyagawa, I. (1994). Differences in seminal parameters in specimens collected via intercourse and incomplete intercourse (coitus interruptus). Fertility and Sterility, 61, 1174-1176.

Received April 16, 2004

Revision received October 30, 2004

Accepted November 2, 2004 